\title{
Effects of Supraphysiological Doses of Anabolic Androgenic Steroids on the Left Ventricles of Male and Female Mice Submitted to Swimming
}

\author{
Laís Cristina Teodoro Jerônimo ${ }^{1}$ Priscila Franco ${ }^{1}$ \\ Wagner Costa Rossi Junior ${ }^{3}$ Alessandra Esteves ${ }^{3}$ \\ 1 Universidade Federal de Alfenas, Alfenas, MG, Brazil \\ 2 Departament of Morphology, Universidade José Vellano, Alfenas, \\ MG, Brazil \\ ${ }^{3}$ Department of Anatomy, Universidade Federal de Alfenas, \\ Alfenas, MG, Brazil
}

Petrus Pires Marques ${ }^{2}$ Flávia da Ré Guerra ${ }^{3}$

\begin{abstract}
Address for correspondence Alessandra Esteves, PhD, Departmento de Anatomia, Universidade Federal de Alfenas, Rua Gabriel Monteiro da Silva, $n^{\circ} 700$, Centro, Alfenas- MG, Brazil, CEP 37130-000 (e-mail: aesteves015@gmail.com).
\end{abstract}

J Morphol Sci 2019;36:2-6.

\begin{abstract}
Keywords

- anabolic steroids

- left ventricle

- mice

- morphometric analysis

The use of anabolic androgenic steroids (AAS) has grown into a worldwide substance abuse problem over the last decades, with the doses taken by illegal users being 10 to 100 times higher than the therapeutic ones. In the present experiment, 60 mice were divided into 3 groups of 20 animals. Group 1 received testosterone cypionate (Deposteron [EMS, São Bernardo do Campo, SP, Brazil]); group 2 received stanozolol (Stanozolol Depot, Landerlan, Lambaré, Paraguay), and group 3 received saline solution), each one composed by 10 males and 10 females, treated once a week and put to swimming thrice a week for 2 months. After euthanasia, their chests were opened, the hearts removed and processed histologically for morphometric analyses. The specimens were cut into 6 different sections and each one was measured with the help of an optical microscope with a 40-fold magnification. For such analyses, the Axiovision Rel. 4.8.2 (Carl Zeiss Microscopy LLC, Peabody, MA, USA) and Axiovision 4 Module Interactive Measurement (Carl Zeiss Microscopy LLC) software were used. The results showed that there was an increase in the diameter of the left ventricles in the male mice treated with Deposteron while in the female animals treated with Winstrol, there was a decrease in the left ventricular diameter in relation to the other two groups. Thus, one can conclude that the use of supraphysiological doses of the given AAS significantly alters the ventricular diameter in both male and female animals, which can cause a considerable change in both heart rate and blood pressure, and potentially induce disorders that are very relevant to the organism.
\end{abstract}

\section{Introduction}

The use of anabolic androgenic steroids (AAS) has grown into a worldwide substance abuse problem over the last decades. Today, the majority of AAS users are not competitive athletes, but, instead, they are typically young to middle-aged men who use them primarily for personal appearance. ${ }^{1}$ The use of AAS is a public health concern for adolescent boys who have suffered bullying by being labeled gay/bisexual. ${ }^{2}$

received

August 22, 2018

accepted

January 28, 2019

published online

March 1, 2019
The doses taken by these users are usually 10 to 100 times higher than the therapeutic ones, bringing forth hyperandrogenism. Although these doses promote increased strength and muscle development, they concomitantly develop hormonal disorders that lead to a variety of harmful consequences. ${ }^{3}$

Among the most striking AAS side effects are the increase in hematocrit and coagulation, causing thromboembolism, intracardiac thrombosis and stroke, as well as other cardiac

Copyright @ 2019 by Thieme Revinter

Publicações Ltda, Rio de Janeiro, Brazil

License terms

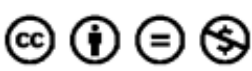


disturbances including arrhythmias, cardiomyopathies, and, possibly, sudden death, adenomas and carcinomas. ${ }^{4}$

The use of anabolic agents causes adverse effects on the musculoskeletal system, increasing the risk of tendon rupture; this is due to the increase of strength and muscle mass. ${ }^{5}$

The anabolic activity of testosterone and its derivatives manifests primarily by its myotrophic action, which results in increased muscle mass by rising protein synthesis in the muscle. $^{6}$

Krieg et $\mathrm{al}^{7}$ analyzed cardiac changes by echocardiogram and observed an increase in the ventricular mass index and in the interventricular septum thickness in AAS users compared with non-users, and also a loss of diastolic function associated with a reduction in peak velocity during the initial phase initial of diastolic filling.

Studies performed with powered athletes by means of echocardiogram examination demonstrated that the cardiac remodeling that occurs as an effect of the use of anabolic steroids is irreversible. ${ }^{8}$

This paper intends to analyze the possible morphometric changes in the left ventricular diameter of male and female mice submitted to swimming that received supraphysiological doses of two types of AAS.

\section{Material and Methods}

In this work, we used 60 Swiss mice (30 males and 30 females) from the Universidade Federal de Alfenas (UNIFAL-MG) bioterium, housed in boxes with 10 animals each, treated with commercial ration and water "ad libitum" (at will) and kept in a light-dark cycle of 12 hours. The present experiment was analyzed and approved by the Ethics Committee for Research and Animal Experimentation (ECRAE) of the University (protocol $n^{\circ} 414 / 2012$ ).

The treatment with AAS consisted of intraperitoneal injections of two types of AAS, as follows: group 1 (10 male and 10 female animals) received a dose of $0.8 \mathrm{mg} / \mathrm{kg}$ of Deposteron (EMS, São Bernardo do Campo, SP, Brazil); group 2 (10 male and 10 female animals) received a dose of $1.8 \mathrm{mg} / \mathrm{kg}$ of Winstrol (Stanozolol Depot, Landerlan, Lambaré, Paraguay), and group 3 (10 male and 10 female animals) received $1.8 \mathrm{mg} / \mathrm{kg}$ saline solution. The animals were treated for 2 months, with the doses being administered twice a week at 2-day intervals. On each of these interposed days, all mice were submitted to swimming for 10 minutes.

After euthanasia by inhalation of isoflurane, the chests of the mice were opened, and the hearts were entirely removed. Finally, they were stored in glass containers immersed in a buffered paraformaldehyde solution ( $\mathrm{pH} 7.4$ ) and remained in this fixative solution for 24 hours. Thus, the specimens were processed following the standardized sequence for a conventional histological procedure: alcohol dehydration, xylol diaphanization, and paraffin inclusion. Each heart was put in a paraffin block and cut into $7 \mu \mathrm{m}$-thickness sections in Jinhua YIDI Medical Appliance CO., LTD (Jinhua City, Zhejiang Province, China) microtome and stained with hematoxylin and eosin. For the morphometric analysis, 6 distinct sections were selected and measured using an optical microscope with 40-fold magnification, and for the morphometric analysis of the ventricular cavity we used the Axiovision Rel. 4.8.2 (Carl Zeiss Microscopy LLC, Peabody, MA, USA) and Axiovision 4 Module Interactive Measurement (Carl Zeiss Microscopy LLC) software. ${ }^{9}$

To evaluate the mean values of the left ventricle areas, according to mice's gender and treatment imposed (research groups), the variance analysis of variance was used. When a significant difference $(p<0.01)$ was observed among the groups while comparing different variables, the Tukey test was used to discriminate differences and/or similarities among the evaluated means. ${ }^{9}$

\section{Results}

According to the graph and photomicrographs (-Fig. 1A and $\mathbf{2 E}$ ), it can be observed that in the male mice treated with

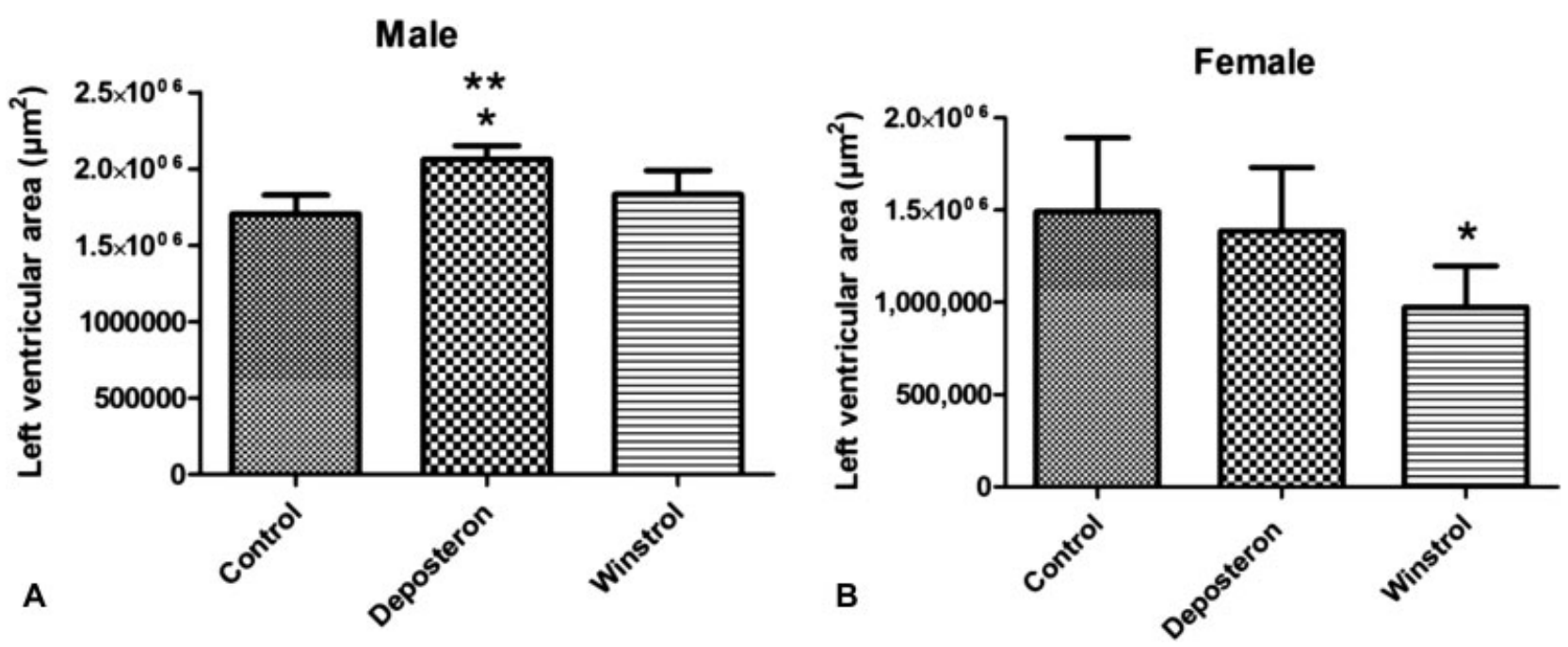

Fig. 1 Comparative graphs of left ventricular diameter in male and female animals, respectively. (A) * Statistically significant differences of control group animals compared with Deposteron animals $(p<0.001)$ and ${ }^{* *}$ Statistically significant differences of Winstrol animals compared with Deposteron animals $(p<0.01)$. (B) Statistically significant differences of control group animals in relation to Winstrol animals $(p<0.01)$. 


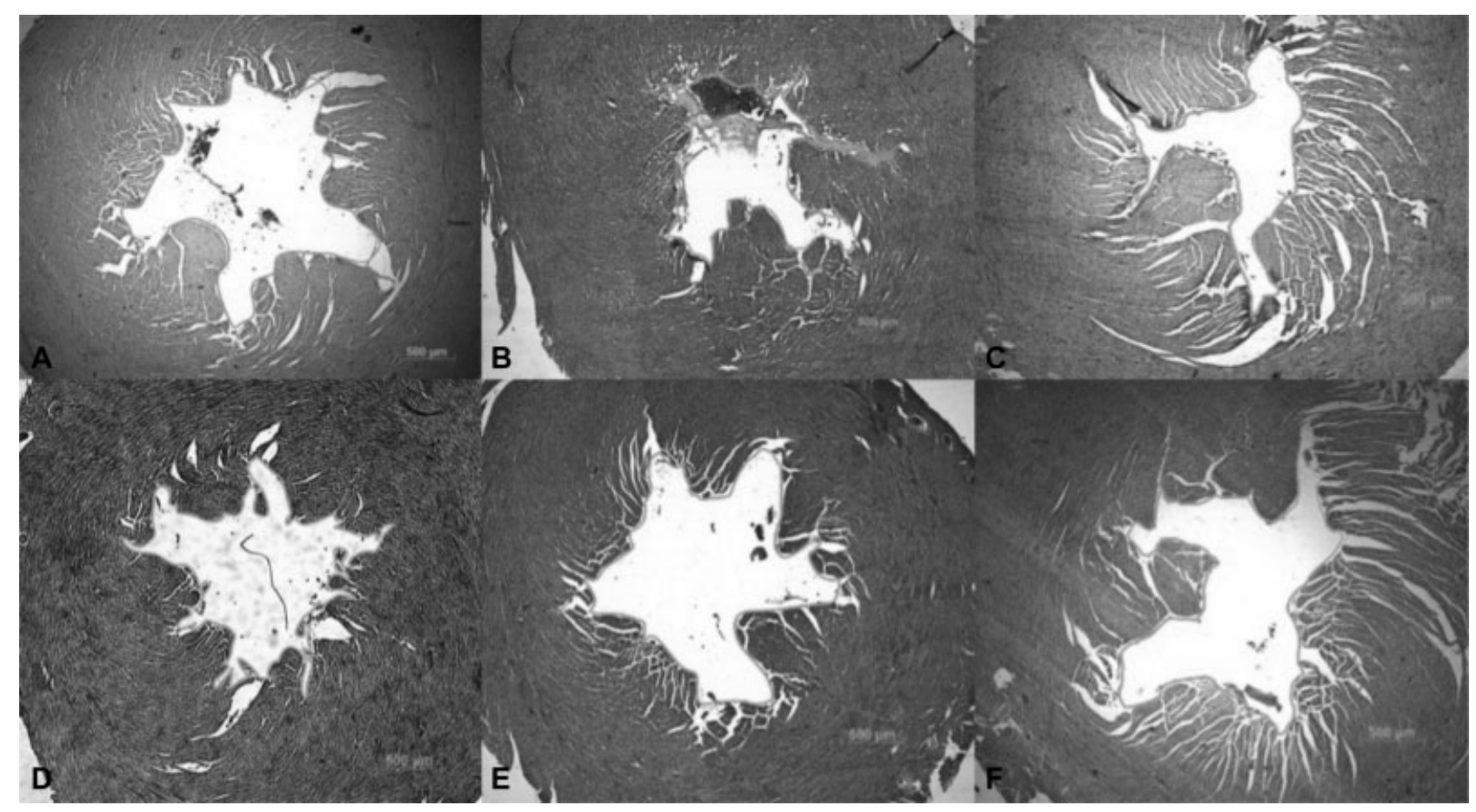

Fig. 2 Photomicrography of the cross-sections of the left ventricle of mice in both sexes and in different groups studied. A: Female control group; B: Deposteron female; C: Winstrol female; D: Male control group; E: Deposteron male, and F: Winstrol male.

Deposteron there was a significant increase $(p<0.001)$ in the diameter of the left ventricle in relation to the control group (-Fig. 2D) and the group treated with Winstrol $(p<0.01)$ (-Fig. 2F).

In the females, the results show that the group treated with Winstrol (-Figs. 1B and 2C) presented a significant decrease in ventricular diameter $(p<0.01)$ in relation to the control (-Fig. 2A) and the Deposteron (-Fig. 2B) groups.

\section{Discussion}

Differences between genders are often ignored and underestimated when studying the cardiovascular system, and these cause biases and losses in the performed researches. ${ }^{10}$ However, previous clinical and epidemiological studies have corroborated and acknowledged gender differences in cardiovascular function and disease. ${ }^{11}$ The causal link between the use of AAS and the occurrence of cardiovascular diseases has been increasingly evidenced through researches, which demonstrate the frequent use of these substances associated with the rise in the occurrence of death due to cardiac arrest among the users. ${ }^{12-14}$ Such studies corroborate the findings in the present study, which show that AAS use may cause morphological changes in the left ventricle and that they can lead to the appearance of cardiovascular diseases.

Cardiac changes in women and men may have been influenced by both dose and time period of administration of the drugs used, and these factors, isolated or together, may have led to different effects in both sexes. However, there are limitations and scarcity of data in the literature regarding the relevance and peculiarities of the different types of AAS.
Neto et al $^{15}$ suggest that the AAS dose is directly related to the aromatization of the testosterone; that is, the higher the dose, the greater the aromatization and the greater cardiac compromise. Pirompol et $\mathrm{al}^{16}$ concluded that cardiac hypertrophy is not related to the dose, but to exposure to the induction of maladaptative heart responses. Therefore, although it was not possible to measure the interference of the dosage, period of use and active principle of the AAS used, the results presented here may induce and contribute to the interest and awakening for future researches.

A second hypothesis consists in the association of AAS action and the activation and increase of the sympathetic autonomic nervous system action. When present in the bloodstream, AAS reach the hypothalamus through the vascular organ of the terminal lamina or through the subfornical organ, structures that do not present a blood-brain barrier, facilitating the absorption and interaction by specific cellular groups of neurons acting on the control of viscera, blood osmolarity, angiotensin II levels and blood pressure. These negative influences of AAS use on the sympathetic modulation have already been evidenced and recorded by Neto et $\mathrm{al}^{15}{ }^{15}$ whose study contributes to and strengthens the results observed here.

The consequences of non-therapeutic and abusive use of testosterone (AAS and its derivatives) are associated with an increase in blood pressure and induction of left ventricular changes, with consequent cardiac hypertrophy, as shown in some studies already performed. ${ }^{17-20}$

Initially, it was expected that there would be no change in the ventricular diameter in females because they have a greater amount of estrogen as a differential characteristic. This hormone is a protective factor for the cardiovascular system, and such concept has already been evidenced in 
some previously published papers. ${ }^{21-23}$ Nonetheless, some authors suggested that the decrease in the diameter of the left ventricle in female animals under supraphysiological doses of the AAS could be due to an increase in the left ventricular wall, leading to a decrease in the ventricular chamber volume with consequent hypertension, resulting in heart failure and left ventricular hypertrophy. 24,25

Another hypothesis that would lead to an increase of muscle mass in females would be based on the same reason observed by Hayward et al, ${ }^{26}$ who administered AAS to women and consequently observed an increase in cardiac muscle mass. This could explain the findings of increased muscle mass with a consequent decrease in diameter in females, in this study, in addition to the fact that the drugs themselves lead to an increase in ventricular mass. Thus, although females have to modulate hormonal protection (estrogen) in the cardiovascular system, such hormone would not have been able to prevent ventricular changes nor would it attenuate the androgenic actions of supraphysiological doses of AAS.

In male animals, it is suggested that the reason for finding the opposite result to that observed in female subjects was due to the drugs investigated in the present experiment, for they increased the left ventricular lumen because of an atrophy of the cardiac muscle and supposed decrease of left myocardial thickness. These effects can lead to chronic ischemia, which drives to fibrosis, reducing heart fiber nutrition, exactly as demonstrated in other studies. ${ }^{27,28}$

Other studies demonstrate that another reason that could lead to an increase in left ventricular diameter in male animals, as found in this study, is that AAS would induce dilated cardiomyopathy, primary heart muscle disease with dilation and change in the contractile function of the left ventricle, which is more prevalent in men than in women. ${ }^{29,30}$

Another factor that could contribute to the increase in left ventricular diameter is that, physiologically, males have a greater amount of endogenous testosterone when compared with females; this factor, added to supraphysiological doses, could lead to toxicity of the cardiac muscle tissue by inducing pro-oxidative actions on the cardiovascular system. ${ }^{10}$

This wide variety of hypotheses may be a reflection of the limitations pertinent to AAS studies and of the morphological consequences to the cardiovascular system caused by the use of AAS. This is due to several reasons, such as the manifestation of the effects, that do not appear in a shortterm period and make it difficult to provide an early diagnosis, as well as the intrinsic factors of the AAS (dose, duration of treatment and active principle) that interfere in their action. ${ }^{1,31-33}$

\section{Conclusion}

Thus, one can conclude that the use of supraphysiological doses of the administered AAS significantly and differently alters the ventricular diameter in male and female animals. Such findings may contribute to elucidate the possible effects and consequences of the indiscriminate use of these drugs concerning the cardiovascular system.

\section{Financial Support}

Fundação de Amparo à Pesquisa do Estado de Minas Gerais (FAPEMIG, in the Portuguese acronym)/UNIFALMG

Conflicts of Interest

The authors have no conflicts of interest to declare.

\section{References}

1 Kanayama G, Pope HG Jr. History and epidemiology of anabolic androgens in athletes and non-athletes. Mol Cell Endocrinol 2018;464:4-13

2 Parent MC, Bradstreet TC. Sexual orientation, bullying for being labeled gay or bisexual, and steroid use among US adolescent boys. J Health Psychol 2018;23(04):608-617. Doi: 10.1177/ 1359105317692144

3 Smurawa TM, Congeni JA. Testosterone precursors: use and abuse in pediatric athletes. Pediatr Clin North Am 2007;54(04):787-796, xii. Doi: $10.1016 /$ j.pcl.2007.05.002

4 Nieschlag E, Vorona E. Doping with anabolic androgenic steroids (AAS): Adverse effects on non-reproductive organs and functions. Rev Endocr Metab Disord 2015;16(03):199-211. Doi: 10.1007/ s11154-015-9320-5

5 Marqueti RC, Paulino MG, Fernandes MN, de Oliveira EM, Selistrede-Araujo HS. Tendon structural adaptations to load exercise are inhibited by anabolic androgenic steroids. Scand J Med Sci Sports 2014;24(01):e39-e51. Doi: 10.1111/sms.12135

6 Kam PC, Yarrow M. Anabolic steroid abuse: physiological and anaesthetic considerations. Anaesthesia 2005;60(07):685-692. Doi: $10.1111 / \mathrm{j} .1365-2044.2005 .04218 . x$

7 Krieg A, Scharhag J, Albers T, Kindermann W, Urhausen A. Cardiac tissue Doppler in steroid users. Int J Sports Med 2007;28(08): 638-643. Doi: 10.1055/s-2007-964848

8 Urhausen A, Albers T, Kindermann W. Are the cardiac effects of anabolic steroid abuse in strength athletes reversible? Heart 2004;90(05):496-501. Doi: 10.1136/hrt.2003.015719

9 Alves DM, Silva MSO, Zavan B, et al. Morphometric analysis of mice's ventricular myocardium submitted to androgenic anabolizing steroids use. Journal of morphological. Science 2015;32 (01):33-36. Doi: 10.4322/jms.071614

10 Tostes RC, Carneiro FS, Carvalho MH, Reckelhoff JF. Reactive oxygen species: players in the cardiovascular effects of testosterone. Am J Physiol Regul Integr Comp Physiol 2016;310(01):R1-R14. Doi: 10.1152/ajpregu.00392.2014

11 Hayward CS, Kelly RP, Collins P. The roles of gender, the menopause and hormone replacement on cardiovascular function. Cardiovasc Res 2000;46(01):28-49

12 D'Andrea A, Caso P, Salerno G, et al. Left ventricular early myocardial dysfunction after chronic misuse of anabolic androgenic steroids: a Doppler myocardial and strain imaging analysis. Br J Sports Med 2007;41(03):149-155. Doi: 10.1136/bjsm.2006.03017

13 Kasikcioglu E, Oflaz H, Umman B, Bugra Z. Androgenic anabolic steroids also impair right ventricular function. Int J Cardiol 2009; 134(01):123-125. Doi: 10.1016/j.ijcard.2007.12.027

14 Thiblin I, Lindquist O, Rajs J. Cause and manner of death among users of anabolic androgenic steroids. J Forensic Sci 2000;45(01): $16-23$

15 Barbosa Neto O, da Mota GR, De Sordi CC, et al. Long-term anabolic steroids in male bodybuilders induce cardiovascular structural and autonomic abnormalities. Clin Auton Res 2018;28(02):231-244

16 Pirompol P, Teekabut V, Weerachatyanukul W, Bupha-Intr T, Wattanapermpool J. Supra-physiological dose of testosterone induces pathological cardiac hypertrophy. J Endocrinol 2016; 229(01):13-23

17 Christakou CD, Diamanti-Kandarakis E. Role of androgen excess on metabolic aberrations and cardiovascular risk in women with 
polycystic ovary syndrome. Womens Health (Lond) 2008;4(06): 583-594. Doi: 10.2217/17455057.4.6.583

18 Cho MH, Jung KJ, Jang HS, Kim JI, Park KM. Orchiectomy attenuates kidney fibrosis after ureteral obstruction by reduction of oxidative stress in mice. Am J Nephrol 2012;35(01):7-16. Doi: 10.1159/ 000334598

19 Elnakish MT, Hassanain HH, Janssen PM, Angelos MG, Khan M. Emerging role of oxidative stress in metabolic syndrome and cardiovascular diseases: important role of Rac/NADPH oxidase. J Pathol 2013;231(03):290-300. Doi: 10.1002/path.4255

20 Frati P, Busardò FP, Cipolloni L, Dominicis ED, Fineschi V. Anabolic Androgenic Steroid (AAS) related deaths: autoptic, histopathological and toxicological findings. Curr Neuropharmacol 2015;13 (01):146-159. Doi: 10.1152/ajpregu.00392.2014

21 Ellis JA, Infantino T, Harrap SB. Sex-dependent association of blood pressure with oestrogen receptor genes ERalpha and ERbeta. J Hypertens 2004;22(06):1127-1131

22 Pedrosa DF, de Rezende LCD, Silva VI, Rangel LBA, Gonçalves WLS, Graceli JB. Efeitos benéficos do estrogênio no Sistema Cardiovascular. Revista Cientifica Perspectivas On Line. 2009;3(12):190-196

23 Apaijai N, Charoenphandhu N, Ittichaichareon J, et al. Estrogen deprivation aggravates cardiac hypertrophy in nonobese Type 2 diabetic Goto-Kakizaki (GK) rats. Biosci Rep 2017;37(05):1-10. Doi: 10.1042/BSR20170886

24 Montisci M, El Mazloum R, Cecchetto G, et al. Anabolic androgenic steroids abuse and cardiac death in athletes: morphological and toxicological findings in four fatal cases. Forensic Sci Int 2012;217 (1-3):e13-e18. Doi: 10.1016/j.forsciint.2011.10.032

25 Soares MCR, Abreu IC, Assenco F, Borges MOR. Decanoato de nandrolona Aumenta a Parede Ventricular Esquerda, mas Atenua o Aumento da Cavidade Provocado Pelo Treinamento de Natação em Ratos. Rev Bras Med Esporte 2011;17(06):420-424. Doi: 10.1530/ JOE-15-0506

26 Hayward CS, Webb CM, Collins P. Effect of sex hormones on cardiac mass. Lancet 2001;357(9265):1354-1356. Doi: 10.1016/ S0140-6736(00)04523-2

27 Dickerman RD, Schaller F, McConathy WJ. Left ventricular wall thickening does occur in elite power athletes with or without anabolic steroid Use. Cardiology 1998;90(02):145-148

28 Mewis C, Spyridopoulos I, Kühlkamp V, Seipel L. Manifestation of severe coronary heart disease after anabolic drug abuse. Clin Cardiol 1996;19(02):153-155. Doi: 10.1002/clc.4960190216

29 Codd MB, Sugrue DD, Gersh BJ, Melton LJ III. Epidemiology of idiopathic dilated and hypertrophic cardiomyopathy. A population-based study in Olmsted County, Minnesota, 1975-1984. Circulation 1989;80(03):564-572

30 Albanesi Filho F. Cardiomiopatias. Arq Bras Cardiol 1998;71(02): 95-107

31 Cecchi R, Muciaccia B, Ciallella C, et al. Ventricular androgenicanabolic steroid-related remodeling: an immunohistochemical study. Int J Legal Med 2017;131(06):1589-1595. Doi: 10.1007/ s00414-017-1589-3

32 Sinha-Hikim I, Artaza J, Woodhouse L, et al. Testosterone-induced increase in muscle size in healthy young men is associated with muscle fiber hypertrophy. Am J Physiol Endocrinol Metab 2002; 283(01):E154-E164

33 Zaugg M, Jamali NZ, Lucchinetti E, et al. Anabolic-androgenic steroids induce apoptotic cell death in adult rat ventricular myocytes. J Cell Physiol 2001;187(01):90-95. Doi: 10.1002/ 1097-4652(2001)9999:9999<00:AIDJCP1057>3.0.CO;2-Y 